Fredrik O. Andersson' / Daniel G. Neely ${ }^{2}$

\title{
Bringing Fiscal Sponsor Activity to Light
}

\author{
${ }^{1}$ Indiana University-Purdue University Indianapolis O'Neill School of Public and Environmental Affairs, Indianapolis, IN \\ 46202-5199, USA, E-mail: fanders@iu.edu \\ ${ }^{2}$ University of Wisconsin Milwaukee, Lubar School of Business, Milwaukee, WI 53201, USA
}

\begin{abstract}
:
We explore the extent to which nonprofits engaging as fiscal sponsors publicly disclose their fiscal sponsor activities. Fiscal sponsors can play an important role in the nonprofit sector by providing capacity support that is often lacking. However, the option to employ a fiscal sponsor is often not well known to smaller entities that would be in the best position to take advantage of the administrative efficiency provided by fiscal sponsors. In reviewing the publicly disclosed information of 74 fiscal sponsors we find that the majority of fiscal sponsors do not disclosure their fiscal sponsorship activity on the Form 990 nor on their website. In order to enhance the sector's understanding of the important role fiscal sponsors play, and ensure fiscal sponsors are held accountable for their fiscal sponsorship activity, we recommend enhanced disclosures of fiscal sponsorship.
\end{abstract}

Keywords: fiscal sponsorship, disclosure

DOI: $10.1515 / \mathrm{npf}-2019-0021$

\section{Bringing Fiscal Sponsor Activity to Light}

The nonprofit sector is often described as a domain with low barriers to entry. As stated by Frumkin $(2002,129)$, "[o]ne of the great attractions of the nonprofit and voluntary sector is that it has become a place where new projects can be designed and implemented by people who are willing to take a chance. Almost anyone with an idea or vision can found a nonprofit or voluntary organization quickly." However, not everyone with visons or ideas yearn to create a new formal (incorporated) nonprofit organization as it requires a number of additional undertakings e. g. recruiting and establishing a board of directors, creating bylaws, submitting applications, and so on. Others are hesitant to launch new nonprofits because they feel they lack the capacity to effectively implement and perform particular nonprofit organizational tasks or functions. Finally, some individuals have the intention to launch a new formal nonprofit but would like to "test the water" before taking the plunge. Fortunately, the nonprofit sector offers a solution to these yearnings and dilemmas. A fiscal sponsor is an already existing nonprofit organization with 501(c)(3) status agreeing to provide a legal home and/or provide various forms of support for currently non-tax-exempt entities. A fiscal sponsor not only helps provide administrative services and oversight but also assumes some or all of the legal and financial responsibility for the activities of the nonprofit entrepreneur (Colvin 2006; Spack 2005). Thus, fiscal sponsorship is an option for eager nonprofit entrepreneurs to carry out new ideas without having to create a new formal venture, or to obtain much needed support and/or guidance during the start-up process, or find time to incubate an idea before moving toward building a full-fledged organization. In addition, to cover the costs associated with being a fiscal sponsor, most sponsors elect to charge some sort of fee for their services (Andersson and Neely 2017). Thus, sponsoring nonprofit entrepreneurs and their projects also represents a potential source of revenue for the fiscal sponsor. It is of course possible the costs of sponsoring a nonprofit entrepreneur can be higher than the administrative fee, and if so it is up to the fiscal sponsor to decide if supporting a nonprofit entrepreneur is worth such net expense. Ultimately, as commented by Spack (2005), fiscal sponsorships have value that goes beyond the sponsor and sponsored project as it serves as a mechanism to pool and coordinate scarce resources in a more efficient manner and allows for innovative approaches and solutions to germinate.

\section{Research on Fiscal Sponsorship}

Fiscal sponsorship is not a new phenomenon. Massachusetts-based Health Research Institute reportedly took on its first fiscally sponsored project in 1957, and it has been more than a quarter century since Colvin (1993)

Fredrik 0 . Andersson is the corresponding author.

(c) BY (c) 2019 Andersson and Neely, published by De Gruyter.

This work is licensed under the Creative Commons Attribution 4.0 Public License. 
first published on how nonprofits can engage in different forms of fiscal sponsorship arrangements. Today there are nonprofits solely devoted to providing and managing fiscal sponsorships (e. g. The Tides Foundation in San Francisco, Community Partners in Los Angeles, and Fractured Atlas in New York), and there is an evolving infrastructure to help nonprofit entrepreneurs identify and connect with fiscal sponsors. According to the San Francisco Study Center, a nonprofit that controls and maintains the Fiscal Sponsor Directory (https:/ / fiscalsponsordirectory.org/), fiscal sponsorship is a growing practice as the pace of sponsors signing up with the directory has accelerated over the past two decades.

In recent years, fiscal sponsorship has also emerged as an area of interest for policymakers. In 2012, an advisory committee to the IRS Exempt Organizations office recognized and recommended fiscal sponsorship as an alternative arrangement to the growing number of nonprofit corporations being formed and seeking IRS approval of their 501(c)(3) exemption. The IRS also, in the wake of hurricanes Sandy and Katrina, proposed using existing organizations, rather than forming new ones, for community relief efforts (Colvin 2012). Moreover, in 2012 the International Humanities Center, a nonprofit serving as a fiscal sponsor for 200 projects, collapsed. The Nonprofit Quarterly (Cohen 2012a, 2012b) reported the failed fiscal sponsor took with it more than $\$ 1$ million in donations that never made it to its intended recipients. The failure attracted public and regulatory attention, and led to a discussion about the potential risks associated with fiscal sponsorships (Takagi 2016).

Yet, despite the long history of fiscal sponsorship activity in the nonprofit sector, the acknowledgement and praise from practitioners for their potential and merits (Blair and Cheplick 2007; Green, Kvaternik, and Alarcon 2006; Spack 2005), and the increasing interest and scrutiny from policy makers, there is an immense shortage of academic research about the fiscal sponsorship phenomenon (Andersson and Neely 2017). Though nonprofit scholars have certainly noted the presence and function of fiscal sponsors (e. g. Gronbjerg, Liu, and Pollak 2010; Kinney and Carver 2007; Ramsundarsingh and Falkenberg 2017), empirical studies analyzing the scope, behavior and impact of fiscal sponsors is virtually non-existent beyond a small number of reports published by fiscal sponsor organizations (Green, Kvaternik, and Alarcon 2006; Krivkovitch 2003).

What we can learn from the existing, albeit limited, research is that fiscal sponsors are found in multiple nonprofit subsectors, they offer a wide array of services and support, and the vast majority of the fiscal sponsors collects some sort of fee for its work (Andersson and Neely 2017; Green, Kvaternik, and Alarcon 2006). If there is one area where fiscal sponsors appear particularly active, it is in arts and culture. Andersson and Neely (2017) examined 184 fiscal sponsors and found more than a third (34.24 \%) listed as Art, Culture and Humanities nonprofits. Indeed, entrepreneurship in the arts sector has been described as highly uncertain and resource-poor, and a field where the ability to connect and make use of resources at hand are essential (De Klerk 2015; Rivetti and Migliaccio 2018). Essig (2014) depicts fiscal sponsorships as a possible component for arts incubators wanting to stimulate arts-based community development. De Klerk (2015) uses the term creative industry bricolage to illuminate the collaborative nature among many artists, and argues that collaboration is often an important element to organize the work of artists more efficiently. Thus, we believe the arts sector offers a promising and relevant setting for better understating fiscal sponsors and the practice of fiscal sponsorship.

\section{Research Purpose and Study Design}

The vantage point for this study is a basic question. Given fiscal sponsors have existed and operated for a long time, are perceived as having an important function to play in the nonprofit sector and for nonprofit entrepreneurs, and allegedly undertake critical and ample economic transactions - why have fiscal sponsorship activities of nonprofit organizations remained a blind spot in nonprofit financial and policy scholarship? In this research note, we posit that a key explanation has to do with the problem of identifying who serves as a fiscal sponsor. As Spack $(2005,24)$ commented, "[b]ecause fiscal sponsorship is by definition a behind-the-scenes service, it is often under the public and philanthropic radar."

Thus, our purpose and primary interest is to explore how fiscal sponsors identify to potential fiscal sponsorees and the general public that they are engaged in the business of fiscal sponsorship. We elect to concentrate our examination on the fiscal sponsor's Form 990 as the Form 990 is (1) a public document required to be disclosed, (2) Is easily accessible to anyone interested via Guidestar, and (3) Provides a set of universally required information that a nonprofit must report. Our contention is that a lack of transparency on the Form 990 regarding Fiscal Sponsor activity would bode ill for the nonprofit sector that could potentially benefit greatly from an increase in fiscal sponsor activity. ${ }^{1}$ Further, a finding that fiscal sponsors are not disclosing their fiscal sponsor activity to the wider public should be of interest to regulators (notably the IRS) and start dialogue on the potential costs and benefits of requiring fiscal sponsors to identify their active fiscal sponsor role explicitly on the Form 990. 


\subsection{Data and Sample}

This study makes use of a novel dataset of nonprofit arts organizations from DataArts (formerly Cultural Data Project). DataArts operates a service called the Cultural Data Profile (CDP) that is being used by thousands of arts and cultural organizations to report financial and operational information. The properties of the DataArts dataset have been described in detail elsewhere (see Kim and Charles 2016). The data in this study are specifically for arts nonprofit organizations reporting in Pennsylvania, California, and Maryland between the years 2005 and 2017. The three states have the best representation of arts and cultural organizations participating in the CDP based on budget size. For the purpose of this research we focus on two questions in the CDP. The first question asks about the total revenue obtained from fiscal sponsorship activities in a given year. The second question asks about any "other" earned revenue in a given year. Coupled with the second question is an option to describe the source of the other revenue reported. For this study, we selected all organizations reporting revenue from fiscal sponsorships in the most recent year of their CDP filing. We also searched the description of "other" revenue using the terms fiscal sponsor, fiscal sponsorship, and fiscal agent. Our initial exploration resulted in 220 individual organizations, of which 106 organizations had entered a value for total revenue obtained from fiscal sponsorship activities in a given year. Of the 106, 31 reported a value of $\$ 0$. One possible interpretation of this finding is that the 31 organizations were engaged in fiscal sponsorship activities but elected not to charge for its services. However, the CDP codebook does not clarify if this is how a value of $\$ 0$ ought to be interpreted. Thus, since we cannot separate $\$ 0$ from a missing value we removed the 31 organizations from our final sample. We also removed one organization that solely focused on providing and managing fiscal sponsorships. 114 organizations indicated having "other" revenue emanating from fiscal sponsorship activity. However, 77 of these organizations reported multiple sources for their other revenue. Wanting to identify how much revenue each arts organization made from their fiscal sponsorships we elected to only keep organizations having "other" earned revenue coming exclusively from fiscal sponsorship activities. This resulted in a sample of 111 arts organizations. Next, we used the EIN number for the 111 organizations to pull their Form 990 based on the latest fiscal year for which they filled out the CDP. We further eliminate 37 organizations that reported fiscal sponsorship revenue before 2008. We included this filter because the Form 990 was extensively revised in 2008 and we wanted the most robust public disclosure document available. This resulted in our final sample of 74 nonprofit organizations.

\section{Analysis}

The 74 nonprofit arts organizations generated on average $\$ 16,640$ in fiscal sponsor revenue. There is quite a range in fiscal sponsorship from the low of only $\$ 7$ to a high of $\$ 306,814$. Table 1 presents the results from reviewing each of the 74 organizations' Form 990 to ascertain how (if at all) the nonprofit discloses their fiscal sponsorship activities.

Table 1: Summary statistics disclosure of fiscal sponsorship activities.

\begin{tabular}{llll}
\hline & N & Mean & s.d. \\
\hline 990 EZ Filers & & & 0.344 \\
PartISummary & 23 & 0.13 & 0 \\
PartIIIProgramAccomp & 23 & 0 & 0 \\
PartVIII2a & 23 & 0 & 0 \\
PartIXFuncExpense & 23 & 0 & 0.422 \\
ScheduleO & 23 & 0.217 & 0.487 \\
NoMention & 23 & 0.652 & 0.395 \\
MentionFSonWebsite & 22 & 0.182 & 0.14 \\
990 Long Form Filers & & & 0.385 \\
PartISummary & 51 & 0.02 & 0.44 \\
PartIIIProgramAccomp & 51 & 0.176 & 0.348 \\
PartVIII2a & 51 & 0.255 & 0.196 \\
PartIXFuncExpense & 51 & 0.137 & 0.505 \\
ScheduleO & 51 & 0.039 & 0.407 \\
NoMention & 51 & 0.51 & 0.204 \\
MentionFSonWebsite & 49 & & \\
\hline
\end{tabular}


First, it should be mentioned that 23 of the 74 (31\%) nonprofit organizations file a Form 990 EZ and not a regular long form 990. This is allowed if an organization reports gross receipts less than $\$ 200,000$ and total assets of less than $\$ 500,000$ at the end of the tax year. For nonprofits filing a Form 990 EZ, 65 \% made no mention of fiscal sponsor services. Of those that did mention fiscal sponsor services, $13 \%$ made a mention on the front page of the Form 990 EZ (generally embedded in other revenue or other expenses). Twenty-two percent included some mention of fiscal sponsor on their schedule $\mathrm{O}$.

While it may not be surprising that there was limited disclosure of fiscal sponsorship services for smaller organizations, we would expect to see a more robust disclosure for nonprofits filing a long Form 990. However, we find that the majority ( $51 \%$ ) of the 51 organizations filing the long form 990 made no mention of fiscal sponsor services. We identified five areas on the Form 990 where organizations made disclosures (note in some cases an organization disclosed fiscal sponsorship services in multiple areas). Perhaps the most prominent display would be the Part III description of programs. Eighteen percent of nonprofits disclosed their fiscal sponsor activities as a part of their program activity. The most common disclosure area was Part VIII detailing other revenue ( $26 \%$ of organizations), followed by the Part IX function expense statement (14\% of organizations), the schedule $\mathrm{O}$ (4\% of organizations), and finally embedded as other revenues and/or other expenses on the front page ( $2 \%$ of organizations). Overall, except for a notable minority of nonprofit organizations that disclosed fiscal sponsorship information as a part of their programmatic activity, most nonprofits made no mention or only a cursory mention of their fiscal sponsorship activity.

To further explore the disclosure practices of fiscal sponsors, we attempted to go the website of each fiscal sponsor for the year covered in our dataset. To access historical website information, we utilized the internet archive wayback machine. The internet archive site allows users to access over twenty years of website history. We attempted to view the website history for the 74 sample organizations. We were unable to access the website history for three organizations. We were able to detect mention of fiscal sponsorship activity for only $18 \%$ of the nonprofit organizations filing a $990 \mathrm{EZ}$ and only $20 \%$ of the nonprofit organizations filing a long form 990 (Table 1). Interestingly, it appears some of the organizations not disclosing fiscal sponsor activity on their 990 did disclose the activity on their website. In 9 out of the 14 cases $(64 \%)$ an organization disclosed on their website they did not also disclose on their Form 990.

\section{Discussion and Implications}

There is growing evidence that fiscal sponsorship is far from a peripheral activity, and as noted in this research note some nonprofit organizations generate a significant amount of revenue due to their sponsorships. Moreover, the fiscal sponsorship model is being promoted as a viable, sometimes even preferred, option for nonprofit entrepreneurs. According to the Trust for Conservation and Innovation $(2014,23)$, the view of nonprofit entrepreneurs using a fiscal sponsor has also shifted: "A decade ago, having a fiscal sponsor might have been a cause for concern, leaving funders wondering what flaw was preventing the project from operating independently." Moreover, the report from the Trust for Conservation and Innovation also notes how the demand for fiscal sponsors is growing and that (22) "[...] a trend toward long-term partnerships between sponsors and charitable organizations has emerged." However, our study also illuminates how it is often difficult, and at times impossible, to identify a nonprofit's fiscal sponsorship activities.

The above observations raise a number of questions and considerations of importance for policymakers and other nonprofit organizational stakeholders. A first question that clearly warrants more research, and ought to be of great interest to several nonprofit stakeholders, is to what extent fiscal sponsors contribute to increased administrative efficiency? In the ongoing (and often animated) debate about nonprofit overhead, fiscal sponsorships stand out as a palpable and feasible option to address some of these overhead concerns. Fiscal sponsorship allows organizations to reduce duplication by pooling and concentrating administrative resources for multiple nonprofit entities under one roof. By sharing the administrative function across multiple nonprofit entrepreneurs, the sponsor organization can acquire, in some cases pretty substantial, unrestricted earned revenue. Thus, fiscal sponsorship sets up a mutually beneficial relationship that not only gives support to nonprofit entrepreneurs but also help the fiscal sponsor maintain or build administrative (or other forms of) capacity.

Second, fiscal sponsorship agreements are not risk-free. As the International Humanities Center's case distinctly illustrates (Cohen 2012a, 2012b), policy makers and regulators must remain vigilant that fiscal sponsorships can have potentially negative effects. However, the lack of transparency when it comes to who serves as a fiscal sponsor makes oversight difficult. Those charged with oversight, such as the IRS and State Attorney Generals, should consider requiring at least some cursory level of disclosure of fiscal sponsorship activity to ensure stakeholders and others are aware of the activity. Larger fiscal sponsors should be encouraged to undergo annual audits to ensure proper accountability of the funds. 
Third, the limited public disclosure of fiscal sponsorship activity is not just a concern for policy makers and regulators. The lack of transparency also camouflages the internal use of resources to other external stakeholders (e. g. funders). Assuming foundations and individual donors have an interest in comprehending how the scarce resources of the nonprofits they elect to support is being utilized, knowing to what extent an organization allocates such resources to incubate and support external nonprofit entrepreneurs seems pertinent. A reporting on the Form 990 of the revenues and expenses associated with the fiscal sponsorship activity is one way to increase accountability of the fiscal sponsorship activity.

Finally, it appears as if the practice of fiscal sponsorship is running ahead of the academic research about fiscal sponsors, and assuming the fiscal sponsorship phenomena is here to stay it ought to alert scholars and policy makers about the need for additional and more robust data on fiscal sponsors. Still, we cannot gain deeper insights unless we can actually identify who is operating as a fiscal sponsor. We therefore welcome steps from the fiscal sponsorship community, as well as from regulators, to implement new ways to explicitly signal fiscal sponsorship activities. A first step would be to ask existing nonprofits filing the 990-EZ and long form 990 to simply check a box indicating they have served in a fiscal sponsorship role during the past fiscal year. Ideally, one would need more detailed information such as how many projects were being sponsored, what type of services is being provided, and how much revenue was generated from the sponsored projects. We feel the often cited quote by Louis Brandeis best sums up our concluding view about fiscal sponsorship disclosure: "Sunlight is said to be the best of disinfectants".

\section{Notes}

1 There are other ways a nonprofit may communicate to the public that they engage in fiscal sponsorship. One common way is to disclose information on Guidestar. As a follow up, we contacted Guidestar in an attempt to obtain a comprehensive list of fiscal sponsors. There response was as follows: "It's possible we can help you but it's actually very difficult - maybe you are keenly aware - to accomplish this task in a straightforward way. In other words, there is not check box or specific data field that a fiscal sponsor must select".

\section{References}

Andersson, F. O., and D. Neely. 2017. "Examining the Role and Diversity of Fiscal Sponsors in the Nonprofit Sector." Nonprofit and Voluntary Sector Quarterly 46 (3): 488-504.

Blair, J., and T. Cheplick. 2007. More than the Money: Fiscal Sponsorship's Unrealized Potential. Berkeley, CA: BTW.

Cohen, R. 2012a. “A Clobal Nonprofit Ponzi Scheme? Lessons Learned from A Fiscal Sponsor's Collapse.” Nonprofit Quarterly Online. Retrived from https://nonprofitquarterly.org/2012/02/14/a-global-nonprofit-ponzi-scheme-lessons-learned-from-a-fiscal-sponsors-collapse/.

Cohen, R. 2012b. “Vanishing Act: Activist Groups Say Donations Disappeared with Fiscal Sponsor.” Nonprofit Quarterly Online. Retrieved from https://nonprofitquarterly.org/management/19616-vanishing-act-activist-groups-say-donations-disappeared-with-fiscal-sponsor.html.

Colvin, G. L. 1993. Fiscal Sponsorship: Six Ways to Do It Right. San Francisco, CA: Study Center Press.

Colvin, C. L. 2006. Fiscal Sponsorship: Six Ways to Do It Right, 2nd ed. San Francisco, CA: Study Center Press.

Colvin, G. L. (2012). Brushes with the Law. Presentation made for the National Network of Fiscal Sponsors in Los Angeles November 8, 2012. Presentation outline available at http://www.fiscalsponsorship.com/brushes_with_the_law.pdf.

De Klerk, S. 2015. “The Creative Industries: An Entrepreneurial Bricolage Perspective." Management Decision 53 (4): 828-42.

Essig, L. 2014. "Arts Incubators: A Typology." The Journal of Arts Management, Law, and Society 44 (3): 169-80.

Frumkin, P. 2002. On Being Nonprofit: A Conceptual and Policy Primer. Boston: Harvard University Press.

Green, R., J. Kvaternik, and I. Alarcon. 2006. Fiscal Sponsorship Field Scan: Understanding Current Needs and Practices. San Francisco, CA: Tides Center.

Gronbjerg, K. A., H. K. Liu, and T. H. Pollak. 2010. “Incorporated but Not IRS-Registered: Exploring the (Dark) Grey Fringes of the Nonprofit Universe." Nonprofit and Voluntary Sector Quarterly 39: 925-45.

Kim, M., and C. Charles. 2016. "Assessing the Strength and Weakness of the Dataarts Cultural Data Profile in Comparison with the NCCS 990 Data." Journal of Public Budgeting, Accounting \& Financial Management 28 (3): 337-60.

Kinney, N. T., and M. L. Carver. 2007. “Urban Congregations as Incubators of Service Organizations.” Nonprofit Management \& Leadership 18 193-214.

Krivkovitch, A. 2003. Fiscal Sponsorship: The State of a Crowing Service. San Francisco, CA: Trust for Conservation Innovation.

Ramsundarsingh, S., and L. Falkenberg. 2017. “An Exploration of Charity/Non-Charity Partnerships in Canada." Canadian Journal of Nonprofit and Social Economy Research 8 (1): 52-70.

Rivetti, F., and M. Migliaccio. 2018. "Arts and Entrepreneurship: Disentangling the Literature." In Entrepreneurship-Trends and Challenges, edited by S. M. Brito, 11-21. London: IntechOpen.

Spack, J. 2005. "How Fiscal Sponsorship Nurtures Nonprofits." Communities \& Banking 16: 22-24.

Takagi, G. 2016. “Fiscal Sponsorship: A Balanced Overview." Nonprofit Quarterly Online. Retrieved from https://nonprofitquarterly.org/2016/01/19/fiscal-sponsorship-a-balanced-overview/.

Trust for Conservation Innovation. 2014. Fiscal Sponsorship: A 360 Degree Perspective. San Francisco: Trust for Conservation Innovation. 